\title{
Configurations of microstrip patch antenna: A Survey
}

\author{
K.Jayanthi ${ }^{1}$, P.Subhashini ${ }^{2}$ \\ Associate professor, Dept. of ECE, SNS College of Technology, Coimbatore, Tamilnadu, India ${ }^{1}$ \\ PG Student [ECE], Dept. of ECE, SNS College of Technology, Coimbatore, Tamilnadu, India ${ }^{2}$
}

\begin{abstract}
The study of microstrip patch antennas has made great progress in recent years. When microstrip antennas are compared with conventional antennas, the microstrip patch antennas have more advantages and better prospects. They are lighter in weight, low volume, low cost, smaller in dimension and ease of fabrication and conformity. Moreover, the microstrip patch antennas can provide dual and circular polarizations, dual-frequency operation, frequency agility, feed line flexibility, beam scanning and omnidirectional patterning. In this paper we discuss about the microstrip antenna and its different types of configurations.
\end{abstract}

Keywords: Microstrip antenna, patch antenna, configuration

\section{INTRODUCTION}

In high performance, aircraft spacecraft, satellite and in missile applications where the performance, size, cost, ease of installation and aerodynamic profiles are constraints, so that the low profile antennas are required.There are many government and commercial applications like mobile and wireless communications have similar specifications. Microstrip antennas are used because of the advantages it possess to meet these requirements. Microstrip antennas are inexpensive and it can be integrated with the Printed Circuit Boards. They are mechanically robust when mounted on rigid surfaces. When particular patch shapes are selected then they are unique in terms of resonant frequency, pattern impedance and polarization. The gain of microstrip antennas can be increased by building a broadside antenna array. By exciting a number of microstrip antenna elements to make them radiate in the same phase at the broadside direction. The efficiency can be improved by increasing the height of the substrate.

\section{MICROSTRIP ANTENNA AND ITS CHARACTERISTICS}

The microstrip antennas are also called patch antennas. These are narrow band and wide beam antennas. It consists of a patch which is very thin and is placed above a ground plane. The patch is very thin $\left(\mathrm{t}<<\lambda_{0}\right.$ where $\lambda_{\mathrm{o}}$ is the free space wavelength). The microstrip antenna is designed so its pattern maximum is normal to the patch(broadside radiator). For a rectangular patch the length $\mathrm{L}$ is usually $\lambda_{\mathrm{o}} / 3<\mathrm{L}<\lambda_{\mathrm{o}} / 2$. The strip and the ground plane are separated by a dielectric sheet as shown in the Fig 2.1.

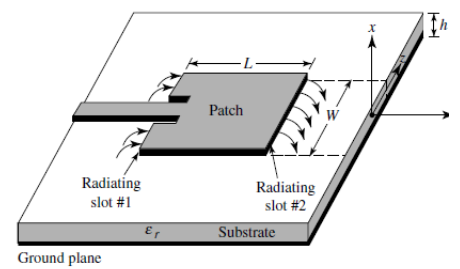

Fig2. 1. Microstrip Patch Antennas
There are many types of substrates that can be used for the design of microstrip antennas and their dielectric constants are in the range of $2.2 \leq \varepsilon r \leq 12$. The thick substrates are usually preferred whose dielectric constant is in the lower end of the range because they provide better efficiency, larger bandwidth, loosely bounded fields for radiation but at the expense of larger element size. The height of the substrate should be in the range $\mathrm{h}<<\lambda_{\mathrm{o}}$, usually $0.003 \lambda_{\mathrm{o}}$ $\leq \mathrm{h} \leq 0.05 \lambda_{0}$. The radiating elements and feed lines are usually photoetched on the dielectric substrate.

\section{III.CONFIGURATIONS OF MICROSTRIP PATCH ANTENNAS}

A. MULTIPLE STACKED ELEMENTS

The multiple stacked microstrip patch antennas have a driven patch and many parasitic elements placed under the driven patch as shown in the Fig 3.1. The elements that are stacked together makes the antenna to operate in different frequencies[3]. The parasitic patches are at different heights under driven patch so that the advantages will be several bands or frequencies, similar bandwidth and gain. The etched capacitor on the driven patch cancels the high inductive effects of coaxial probe and thus the antenna matched to self impedance of $50 \mathrm{ohms}$.

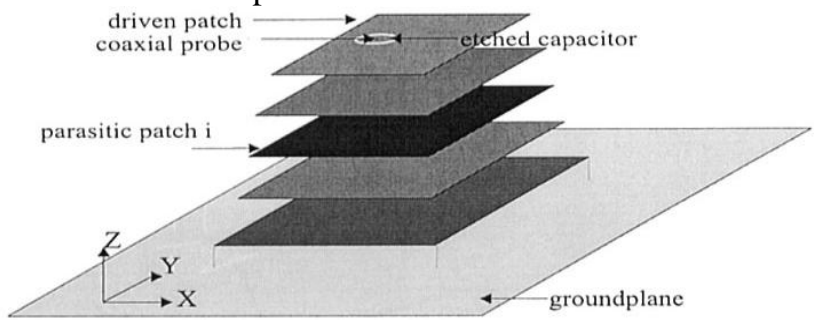

Fig3.1. Multiple stacked patch elements

B. DUAL AND MULTIBAND U-SLOT PATCH ANTENNAS

A wideband patch antenna is fed by a L-probe can be designed for dual and multiband applications. U-slot was designed to introduce band notch for minimizing interference. By cutting U-slots on the patch band notches are introduced within the matching band resulting in 
multiband operation. When a U-slot is made on the patch a notch is introduced and a dual band antenna is obtained[4]. When two U-slots are made two notches are introduced and a triple band antenna results as shown in the Fig 3.2.

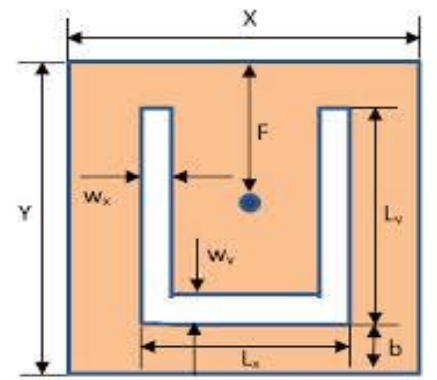

Fig 3.2. U-slot patch antenna

\section{DUAL-BAND FOUR ELEMENT BROADSIDE \\ PATCH ANTENNA ARRAYS}

The patch antenna array is built by feeding four element patch antennas through a feeding patch by parasitic coupling as shown in the Fig 3.3. Similar to Electrically Steerable Passive Array Radiator which means a driven element is directly excited from the power source and other radiating elements are excited through mutual coupling.

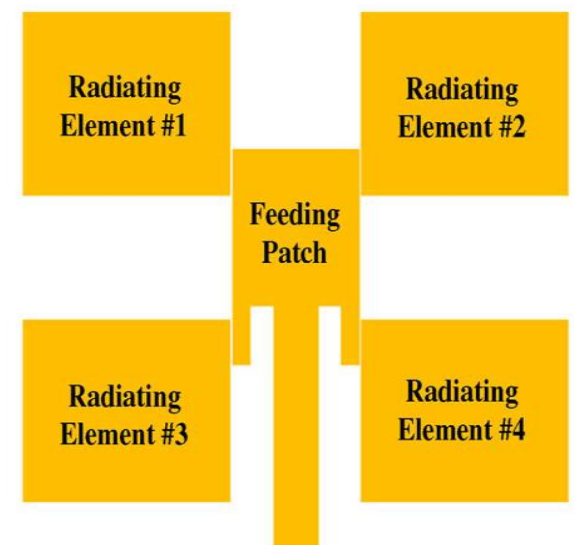

Fig3.2 Four element parasitically fed patch antenna array Here similar to ESPAR energy is fed through the center patch to the four antenna elements through capacitive gaps[4]. The feeding network is simpler.

\section{V.CONCLUSION}

A detailed survey on different configurations of microstrip patch antennas is presented in this paper. Some effects of the disadvantages like low power handling and lower gain can be overcome through an array configuration.

\section{REFERENCES}

[1] Sai Ho Yeng, Alejandro Garcia-Lamperez,Tapan Kumar Sarkar and Magdalena Salazar Palma "Thin and Compact Dual-Band Four Element Broadside Patch Antenna Arrays",IEEE Antennas and Wireless Propagation Letters, vol.13,2014.

[2] W. C. Mok, S. H. Wong, K. M. Luk, and K. F. Lee, "Single-layer single-patch dual-band and triple band patch antennas," IEEE Trans.Antennas Propag., vol. 61, no. 8, pp. 4341-4344, Aug. 2013.

[3] J. Anguera, G. Font, C. Puente, C. Borja, and J. Soler, "Multifrequency microstrip patch antenna using multiple stacked elements," IEEE Microw. Wireless Compon. Lett., vol. 13, no. 3, pp. 123-124,2003.
[4] K. F. Lee, S. L. S. Yang, and A. Kishk,"Dual- and multi-band U-slot patch antennas," IEEE Antennas Wireless Commun. Lett., vol. 7, pp. 645-648, 2008.

[5] K. F. Lee, K. M. Luk, K. M. Mak, and S. L. S. Yang, "On the use of U-slots in the design of dual-and triple-band patch antennas," IEEE Antennas Propag. Mag., vol. 53, pp. 60-74, Jun. 2011.

[6] M. Midrio, S. Boscolo, F. Sacchetto, C. G. Someda, A. D. Capobianco, and F. M. Pigozzo, "Planar, Compact Dual-Band Antenna for Wireless LAN Applications" IEEE Antennas and Wireless propagation letters, vol. 8, 2009.

[7] Dan Yu, Shu-Xi Gong, Yang-Tao Wan, and Wen-Feng Chen "Omnidirectional Dual-Band Dual Circularly Polarized Microstrip Antenna Using TM01 and TM02 Modes," IEEE Antennas and Wireless propagation Letters, vol. 13, 2014.

[8] Y. M. Pan, S. Y. Zheng, and B. J. Hu "Wideband and Low-Profile "Omnidirectional Circularly Polarized Patch Antenna," IEEE Transactions on Antennas and Propagation, vol. 62, no. 8, august 2014.

[9] Kin-Fai Tong, Kwai-Man Luk, Kai-Fong Lee, Richard Q. Lee "A Broad-Band U-Slot Rectangular Patch Antenna on a Microwave Substrate," IEEE Transactions on Antennas and propagation, vol. 48 , no. 6 , june 2000 